\title{
Floral attraction
}

\author{
An Enthusiasm for Orchids: Sex and \\ Deception in Plant Evolution \\ by John Alcock \\ Oxford University Press: 2006. 320 pp. \\ E17.99,\$29.99
}

\section{Sebsebe Demissew}

Botanists have devoted much time, energy and money to understanding the complexities of evolution, adaptation and speciation. In my view, orchids provide the best examples of evolutionary adaptations, because of their intricate relationships with their pollinators.

Anyone trying to learn about orchids could, however, easily be put off by the terminology and the bizarre floral characters unique to these plants. What's needed is a book that presents these complex floral characters in an understandable and attractive way. John Alcock's book An Enthusiasm for Orchids does this.

The book provides evidence for plant evolution at a global level, showing many captivating orchid flowers that are mainly restricted to the southwestern part of Western Australia. Spider orchids, sun orchids, hammer orchids and 'flying ducks' serve as examples of remarkable individual adaptations to their pollinators.

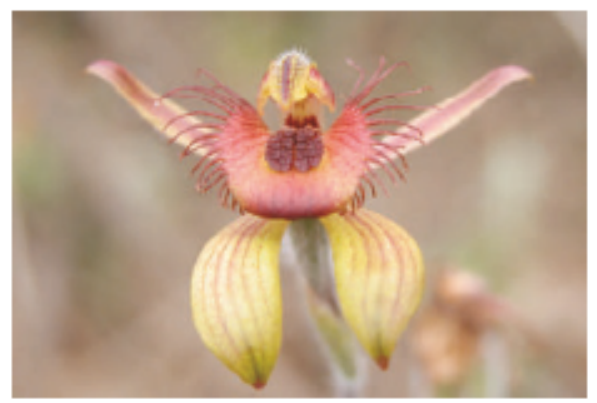

Designed to deceive: an Australian bee orchid, Caladenia discoidea.

Alcock explains why this part of Australia has such diversity and discusses the speciation.

Since the publication of Charles Darwin's The Origin of Species, many authors have provided examples in support of natural selection, and others have tried to refute it. This book certainly belongs in the former category, providing vivid examples of adaptation shaped by natural selection promoting reproductive success.

Field biologists face many problems on field trips, such as difficulty in finding the right location and the species they are looking for, and not being sure whether the species they find is new to science or not. Few researchers would transmit this information to others, but Alcock gives a full account of his experience that will be og useful for anyone wishing to explore the south- $\Sigma$ west corner of Australia. I visited Western Australia in the 1980s and was fascinated by the banksias and sundews, for example, that Alcock also mentions. Although I am currently more involved with petaloid monocots, such as aloes, with my interest in orchids this book has inspired me to revisit southwestern Australia when the opportunity arises.

The book is easy to read and has many beautiful illustrations. It shows adaptations found in different groups of plants: orchid flowers lure their pollinators by various means, sundews have folding leaves to capture insects as prey, and plants also rely on winged seeds or the explosion of dried capsules for dispersal.

For an overview of the concepts of adaptation and maladaptation, a brief history of evolution in general, and a good look at the hotspots, biodiversity and conservation of orchids in southwestern Australia in particular, this is the book to read.

Sebsebe Demissew is keeper of the Ethiopian National Herbarium and heads the Ethiopian Flora Project, Addis Ababa University, P.O. Box 3434, Addis Ababa, Ethiopia.

\section{The maths mentor}

\section{Letters to a Young Mathematician}

by lan Stewart

Basic Books: 2006. 224 pp. \$22.95, £13.99

\section{Rhian Parker}

Mathematics seems to be something that you either get or you don't. I was lucky: I've always found the concepts behind maths easy to understand, and in some way natural. A degree in maths was always what I was going to do, a master's followed, and the possibility of staying in academia is something I've been considering since I left school. There are already a number of 'popular' maths books (many by Ian Stewart), which gave me a good idea of what the transition from school to university maths would be like. But I could do with more information on the more personal aspects of how one goes about doing maths, and the possibilities for being a professional mathematician, even as I approach the end of my master's.

In Letters to a Young Mathematician, Stewart writes to a fictional girl, Meg, following her career in mathematics from high school to a tenured position. Each letter covers a different topic, answering concerns that Stewart feels young mathematicians may have.

He starts on familiar ground with the differences between school and university mathe- matics, and moves on to what to expect from a maths degree. These are mainly discussions on proof - what it is, why we feel the need to do it, and how Stewart likes to think of it. As Meg progresses, the letters move on to what professional mathematicians do and how they do it. A recurring theme is what maths actually is, with letters at times verging on philosophy.

As a young female mathematician, I found the book somewhat disappointing. It offers good advice in some areas, such as how to work at maths at university level. But there is a general lack of information - Stewart tends to waffle slightly. For instance, the letter about the career ladder is written in the context of finding a good $\mathrm{PhD}$ supervisor. Nowhere does he describe the actual professional ladder and where you can expect a career in mathematics to take you - information that would be welcome to a student deciding on a degree subject, and to an undergraduate deciding between an academic career and moving out. There is also too much jargon: Meg gets a postdoc position, then an assistant professorship, and ends up with tenure. I wouldn't have understood any of these terms as a 17 -year-old.

The book also suffers from being written entirely for a US audience, from the spelling to the description of how your career pro- gresses. This is a real shame, as the differences are at times enough to make the book all but useless to students outside the United States.

The letter in which Stewart tells Meg how to teach undergraduates should be compulsory reading for all lecturers and tutors. The advice seems to get better the further Meg gets. There is an amusing chapter on learning from others' mistakes, and his description of the community of mathematicians is true and appealing.

But the book's major problem is the timescale. Meg ages 15 or 20 years; the reader a few hours. The first few chapters are good for school pupils and as an introduction to higher level' mathematics. The next few can be read when you're getting to the end of your degree, and then again when you gain your $\mathrm{PhD}$. But at any one time, the book has too little to offer, and the rest of it is either below you or not written in a general enough way to interest you.

And what saddened me was that Letters to $a$ Young Mathematician did not leave me with a sense of wonder and beauty, or even pride, in mathematics, as other books have. For that I would recommend Paul Hoffman's The Man Who Loved Only Numbers (Fourth Estate, 1998), Robert Kanigel's The Man Who Knew Infinity (Scribner, 1991) and most of Stewart's other books, especially The Magical Maze (Weidenfeld \& Nicolson, 1997).

Rhian Parker is fourth-year mathematics student at The Queen's College, University of Oxford, Oxford OX1 4AW, UK. 